\title{
ANÁLISE E APLICAÇÃO BIBLIOMÉTRICA NA ADMINISTRAÇÃÓ E ÁREAS AFINS: UM LEVANTAMENTO NACIONAL
}

\section{ANALYSIS AND BIBLIOMETRIC APPLICATION IN ADMINISTRATION AND RELATED AREAS: A NATIONAL SURVEY}

Recebido em: 03/08/2018.

Aceito em: 04/10/2018.

Ismael de Mendonça Azevedo'

\section{RESUMO}

A técnica do estudo bibliométrico se firmou no meio científico e acadêmico no século passado. Porém, nos últimos anos, as ciências administrativas e áreas afins têm apresentado a análise bibliométrica como prática comum em suas pesquisas. Esta pesquisa objetiva um levantamento da produção nacional de artigos científicos, na área das ciências administrativas e afins, que foram elaborados em função das características dos métodos bibliométricos. Como fonte de informação se utilizou dos anais dos eventos patrocinados pela ANPAD entre 2012 a 2016 e das informações da base de pesquisa Spell entre janeiro de 2004 e junho 2018. O trabalho tem o método descritivo como meio e se apoia nas análises quantitativas e estatísticas de medição dos índices de produção científica. A pesquisa apontou para um aumento na quantidade de trabalhos bibliométricos apresentados nos eventos nacionais patrocinados pela ANPAD, bem como uma evidenciação da presença em periódicos, sobretudo, entre os anos de 2007 e 2016, sendo este último ano que apresentou maior quantidade de trabalhos em periódicos, com um total de 51 artigos científicos, que se utilizaram da análise bibliométrica para avaliação. Os resultados mostram a presença de 272 artigos publicados em 85 periódicos, porém apenas 19 periódicos apresentando 5 ou mais artigos, e 18 autores com participação em 4 artigos ou mais. Por fim, com estes resultados é possível evidenciar que a técnica bibliométrica tem sido explorada em função da sua importância como método eficaz para a gestão da informação e do conhecimento nas ciências administrativas e áreas correlacionadas.

Palavras-chave: Análise bibliométrica. Bibliometria. Pesquisa em Administração.

1 Mestrando em Administração pela Universidade Potiguar (UnP). Docente da Universidade Potiguar (UnP). E-mail: ismaeldemendonca@bol.com.br 


\section{ABSTRACT}

The technique of bibliometric study was established in the scientific and academic milieu in the last century. However, in recent years, as the administrative sciences and areas have taken a bibliographic analysis as history in their research. This research aimed at a survey of the national production of scientific data in the area of administrative and related sciences, which were elaborated according to the characteristics of bibliometric methods. As a source of information it is used in the annals of events sponsored by ANPAD between 2012 to 2016 and information from the spell search database between January and June 2018. The work has the method of analysis and the quantitative and statistical statistics of the index of scientific production. The research was aimed at increasing the amount of bibliometric work of the clients, having as indicators the annual indicators of 2007 and 2016, the latter being the last one that the largest amount of work in periodicals., with a total of 51 scientific articles, which use bibliometric analysis for evaluation. The results show the presence of 272 articles published in 85 journals, but only 19 journals presenting 5 or more articles, and 18 authors with participation in 4 articles or more. Finally, the results obtained are evidenced as a bibliometric technique explored in its function as effective for the management of information and knowledge in the areas of sciences and correlated areas.

Keywords: Bibliometric analysis. Bibliometria. Research in Administration.

\section{INTRODUÇÃO}

A era da informação que data da década de 1980 cedeu lugar a era do conhecimento na década seguinte, 1990, e, de maneira acentuada, os anos 2000 apresentaram ao mundo o poder da tecnologia das redes de bases de pesquisas conectadas e gestoras de estudos, pesquisas, trabalhos etc. Não obstante, esta evolução tecnológica trouxe ao mundo das pesquisas toda a volatilidade desta geração do conhecimento, pois as pesquisas vêm se atualizando em uma velocidade cada vez maior, fato que faz um estudo se tornar obsoleto mais rapidamente.

É neste ínterim, a partir da ampliação do acesso aos dados, a informações e ao conhecimento, que a produção científica mundial cresce de maneira acentuada e, sobretudo, que os pesquisadores precisam envidar esforços na organização e sistematização de toda a produção científica disponível para facilitar o acesso ordenado, além de economizar tempo no sentido de gerenciamento de suas pesquisas com eficiência. Para conseguir este feito, o desafio dos pesquisadores é se apropriar de métodos que sejam auxiliares na organização dos estudos disponíveis.

É diante desta revolução nas pesquisas que o campo da Administração, atualmente a graduação com a segunda maior quantidade de graduandos a nível nacional 
(INEP, 2016) e que faz parte da quarta maior área de pós-graduação stricto sensu do país (LIEVORE; PICININ; PILATTI, 2017), busca métodos eficientes para auxiliar a organização, mensuração e estratificação das características da literatura presente em uma determinada área. Que, desta forma, funciona como uma fonte de apontamentos, montagens ou apresentações de arcabouços teórico-científico das temáticas pesquisadas.

Um destes métodos que tem uso destacado, em especial nas ciências administrativas e afins, não é recente, pois Pritchard (1969) determinou sua forma o nome no final da década de 1960, que é a Bibliometria. Para Pritchard (1969) bibliometria é a aplicação de métodos matemáticos e estatísticos de maneira explicita em todos os estudos que buscam quantificar os processos de comunicação escrita no campo da ciência da informação. Desta forma, o método bibliométrico vem se sobressaindo, pois é uma ferramenta capaz de apresentar bons resultados quando da necessidade de articular características específicas e essenciais de trabalhos mesmo em grandes volumes de trabalhos, com a finalidade de apresentar o status quo de um determinado fenômeno, de uma temática, de uma literatura para uma área, dentre outros. A aplicação da análise bibliométrica como uma metodologia, funciona como um instrumento aglutinador de informações pertinentes à área que se pretende colaborar, desenvolver, estudar ou pesquisar.

A administração e áreas afins vêm apresentando grande quantidade de pesquisas cujo método seguiu os preceitos da bibliometria e, notório conhecimento tem sido divulgado em eventos científicos e periódicos nacionais. A quantidade de trabalhos encontrados é elevada, portanto, se faz essencial destacar neste estudo as características nacionais dos trabalhos existentes. Ao final será possível norteia novos pesquisadores que possivelmente se interessem pelo método bibliométrico no âmbito da administração e áreas correlatas, de maneira a direcionar quais periódicos têm sido mais profícuos para esta temática, quais autores publicaram mais artigos nos últimos anos, quais os eventos nacionais publicaram em seus anais trabalhos de cunho bibliométrico, dentre outros aspectos relevantes. Portanto, a pesquisa objetiva uma analise da produção nacional de artigos científicos, na área das ciências administrativas e afins, que foram elaborados em função das características dos métodos bibliométricos.

A pesquisa se alicerça como relevante em função da constante presença de estudos e trabalhos bibliométricos nos eventos científicos promovidos, sobretudo, pela Associação Nacional dos Programas de Pós-Graduação em Administração - ANPAD, além da evidente presença desta temática nos periódicos científicos nacionais, o que torna emergente investigar as características destas pesquisas a nível nacional como forma de apresentar um arcabouço atual e pertinente aos interessados por este tipo de estudo na referida área. 


\section{REFERENCIAL TEÓRICO}

A gênese da bibliometria remota de modelos e termos utilizados na biologia, psicologia e economia, como biometria, psicometria e econometria, respectivamente. Na década de 1920 o termo sociometria foi bastante utilizado para se analisar os problemas relativos à sociedade, cujo principal objetivo foi o estudo matemático para análise quantitativa de propriedades psicológicas no nível da comunidade. Desta forma, a sociometria se transformou na ciência métrica que mais se difundiu nas ciências, sobretudo, na sociologia, psicologia, educação e administração até meados de 1960. Contudo, sua influência métrica e estatística chega até a biblioteconomia como uma forma de mensurar características da bibliografia e passa a ser chamada de bibliometria. A bibliometria então se torna a nova forma de designar a análise de métodos matemáticos e estatísticos na literatura que estava difundida e organizada de maneira escrita (MORENO, 1962; PRITCHARD, 1969; URBIZAGÁSTEGUI ALVARADO, 1984).

Dentro das referências conceituais de trabalhos com foco na bibliometria é possível destacar três importantes estudiosos que desenvolveram as primeiras leis capazes de nortear de forma precisa as primeiras análises métricas da literatura escrita à época, e que consequentemente seus estudos se tornaram fonte de inspiração para quem se serve deste método até os tempos atuais, são eles: Lotka, Bradford e Zipf. Dada à descoberta e a importância dos feitos destes autores, suas leis levam seus nomes. $\mathrm{O}$ primeiro autor fundou o que ficou conhecida como lei de Lotka, que visa descrever e analisar a produtividade dos autores em determinada área. Já a lei de Bradford tem por finalidade a descrição da distribuição da literatura escrita em periódicos, dentre outros, mas numa área específica; enquanto a lei de Zipf busca descrever a frequência no uso de palavras num determinado texto (URBIZAGÁSTEGUI ALVARADO, 1984).

As percepções de Lotka para a fundamentação do que ficou conhecida como sua Lei, datam do início do século passado quando o autor despertou curiosidade em meio a aspectos importantes quanto à produtividade de alguns cientistas que se faziam presentes na conferência Chemical Abstracts entre 1909 e 1916. Lotka fez a contagem de quantos autores estavam presentes naquela conferência e identificou que uma larga produção de estudos e pesquisas da literatura científica apresentada naquele momento estava relacionada a um pequeno número destes autores e, por outro lado, muitos autores expostos e presentes no mesmo ambiente estavam relacionados à apresentação de um pequeno número de produção científica. Esse fenômeno chamou a atenção e foi apresentado ao mundo por Lotka em 1926 e, a partir de então, estudos que visam identificar quanto à produtividade de autores passaram a ser caracterizados ou auxiliados pela lei de Lotka (LOTKA, 1926; COILE, 1977).

Para Lotka esta mensuração de produtividade não estava apenas expondo o ranking de autores mais profícuos, mas a qualidade dos trabalhos expostos, já que o autor mais produtivo normalmente era o que tinha maior profundidade em suas pesquisas, enquanto os demais faziam pesquisas mais rasas ou com menos densidade na 
discussão de conteúdo (COILE, 1977). Tais descobertas chamaram a atenção do meio científico e um pouco mais tarde, Goffman e Newill (1964), revelaram seus estudos a partir das descobertas da Lei de Lotka, que foi fundamentada dentro de uma perspectiva metaforizada pelo processo epidêmico para caracterizar a transmissão de ideias entre pesquisadores, que funciona como um processo infeccioso e ocasiona o surgimento de novos pesquisadores em determinada área a partir da exposição do potencial pesquisador a uma pesquisa de interesse.

Posteriormente a Lei de Lokta, surge a Lei de Bradford em 1934. Bradford partiu do pressuposto de que assim como poucos autores produzem muitos trabalhos e assim servem como referência para uma área, ao tempo em que muitos autores produzem poucos trabalhos, era notável que um núcleo formado por poucos periódicos divulgavam muitos trabalhos sobre uma determinada área, enquanto muitos periódicos divulgavam poucos trabalhos sobre a esta mesma área. Naquele momento, Bradford aplicou cálculos matemáticos em seus estudos para verificar a proporção nas quais artigos de um determinado tema apareciam em certos periódicos, o foco de interesse era mensurar a distribuição dos artigos a partir de variáveis de proximidade ou de afastamento, o que ficou conhecido como a lei da dispersão ou Lei de Bradford. Com seus estudos, o autor descobriu que um núcleo menor de periódicos estava relacionado de maneira próxima a um mesmo assunto, enquanto um núcleo maior estava dispersando a temática, e assim não se tornavam periódicos especializados (BRADFORD, 1934; ARAÚJO, 2006).

O terceiro autor, Zipf, surge com seu trabalho em 1949 para descrever a relação que existia entre as palavras em um determinado e longo texto. Para o autor era notável que uma produção textual relativamente grande, continha uma ordem de série de palavras, contudo, que era uma relação possível de se estimar de maneira que fosse plausível delimitar a região de concentração de termos de indexação. Com seus estudos, foi possível encontrar uma correlação entre o número de palavras diferentes e a frequência com que estas palavras apareciam no texto analisado. Ele descobriu, dentre outras coisas, que a posição de uma determinada palavra multiplicada pela frequência que a palavra aparecia no texto era igual a uma constante de aproximadamente 26.500 (ZIPF, 1949; ARAÚJO, 2006; GUEDES, 2012). Desta forma, para Zipf era possível analisar as palavras de um texto, como forma de indexação do texto em uma temática específica.

De maneira geral, as três primeiras leis que norteiam a bibliometria, permitem estimar a produção de autores, pois considera que alguns autores de pesquisas apresentam supostamente um maior prestígio em determinada área do conhecimento, já que produzem muito em detrimento de muitos pesquisadores que supostamente têm menor prestígio (LOTKA, 1926), também auxiliam para mensurar a ocorrência de pequeno núcleo de periódicos que se apresenta com maior grau de relevância em uma determinada área do conhecimento, pois divulgam maior número de artigos específicos (BRADFORD, 1934), e por fim, é possível estimar a frequência com que palavras 
ocorrem em textos, de maneira que se possa delimitar a região de concentração de termos de indexação, dentre outros (ZIPF, 1949; GUEDES, 2012).

Foi a partir destas primeiras leis, que ao longo do século passado, pesquisadores da técnica bibliométrica desenvolveram novos métodos e leis capazes de auxiliar na mensuração de outros aspectos relevantes da literatura científica, tais como a lei do Elitismo, que busca descrever sobre o fato de que um pequeno grupo de artigos recentes se forma como um núcleo que congrega uma seleta parte da literatura, pois passa a ser citado em outros artigos mais recente de maneira relacionada a uma parte maior da literatura mais antiga. Em detrimento disso, uma maior parte dos artigos mais recentes não é citada, de maneira que estatisticamente é possível provar que a cada ano pelo menos $10 \%$ dos artigos não serão citados e desaparecerão (BRAGA, 1973). E a lei da Obsolescência ou Vida Média (BURTON; KLEBER, 1960), que foi desenvolvida para descrever exatamente a queda da validade dos materiais publicados ou a utilidade das informações no decorrer de certo período de tempo (URBIZAGÁSTEGUI ALVARADO, 1984).

O fato é que presente no meio científico, os estudos métricos são formados por um conjunto de métodos de avaliações das informações científicas produzidas em diferentes níveis e suportes, norteados por ferramentas de análise de informações quantitativas. São estudos que se apoderam da ciência da informação, matemática, estatística e computação. Mas podem ser tidos como estudos de natureza teórico-conceitual quando contribuírem com novos conceitos e indicadores para o avanço do conhecimento da própria temática analisada. Pois um pesquisador pode usufruir da ordenação baseada na bibliometria para apresentar ponderações e análises concernentes à área de estudo. Portanto, o estudo bibliométrico não se limita como um estudo estatístico com a finalidade em si mesmo, quando teórico-conceitual têm como característica a apresentação de cunho metodológico ao utilizar suas análises e proposições como pilares para sustentação aos trabalhos de caráter teóricos (OLIVEIRA; GRÁCIO, 2011).

Desta forma, é necessário desmistificar a bibliometria como um fim matemáticoestatístico em si. Ela deve ser tida como uma ferramenta metodológica acessória para o pesquisador, que precisa ter a capacidade de desenvolver, a partir dos resultados obtidos com a ferramenta, um arcabouço teórico da temática pesquisada de maneira que sirva como fonte inestimável de conceitos e possibilidades para outros estudos acerca do que se propôs estudar. Pois, se tratada como uma ferramenta estatística acessória nas pesquisas, a bibliometria possibilitará a organização do status quo de uma ciência, e permitirá aglutinação de conceitos para promoção de novas evoluções conceituais.

\section{MÉTODOS}

Conforme previamente informado, o trabalho se constitui em um levantamento nacional a partir da produção acadêmica na área das ciências administrativas. Para atingir o objetivo planejado, portanto, é uma pesquisa com finalidade exploratória, 
pois na pesquisa exploratória não se trabalha com a relação entre variáveis, mas com o levantamento da presença das variáveis e da sua caracterização quantitativa ou qualitativa (KÖCHE, 2011).

A idealização do processo metodológico ocorreu com a escolha do corpus da pesquisa que, para atingir os objetivos propostos, ficou definida pela produção nacional com escopo baseado na técnica bibliométrica que estivesse publicado em periódicos e eventos na área das ciências administrativas e afins. Para participar do levantamento elaborado se considerou todos os artigos científicos que estavam presentes nos anais dos eventos promovidos e apoiados pela Associação Nacional de Pós-graduação e Pesquisa em Administração (ANPAD), dada a relevância desta instituição no apoio à publicação de pesquisas em congressos nacionais, referentes ao período compreendido entre 2012 e 2016. Outrossim, com o intuito de ampliar o arcabouço do estudo, optouse por utilizar os artigos científicos que estavam presentes na base de pesquisa Spell, que atua na indexação de periódicos da produção científica nacional genuínas da área de Administração Pública e de Empresas, Contabilidade e Turismo, entre janeiro de 2004 e junho de 2018.

Buscas preliminares foram feitas A escolha destes materiais presentes nos anais para análise se justifica dada a importância dos eventos e ao grande número de trabalhos elaborados pelos estudiosos, pesquisadores e cientistas, que, por consequência da submissão, foram aprovados mediante rigorosa avaliação de corpo docente científico selecionado pela instituição, que adota de cuidado, rigor e zelo antes da aprovação. Por outro lado, a escolha da base Spell se deu, pois, é a maior base de indexação nacional voltada exclusivamente para a área da ciência administrativa e áreas correlatas, com isso reúne grande parte dos periódicos nacionais, totalizando 121 periódicos. Porém, para garantir à qualidade da escolha de ambas as fontes, buscas preliminares de materiais foram feitas para mensurar a presença e o quantitativo destes materiais com a utilização dos descritores que mais reportavam respostas adequadas à análise que seria feita posteriormente.

Após a definição das fontes com base em sua relevância, deu-se continuidade ao procedimento de preparação do arcabouço com o material que faria parte do corpus objetivado pela pesquisa. Para tanto, foi elaborado um minucioso levantamento nos anais presentes no site da ANPAD e dos periódicos na base Spell com a finalidade de encontrar artigos científicos com a temática voltada para a técnica bibliométrica a partir do cruzamento dos descritores definitivos para a busca, que foram: "bibliometria”, "bibliométrica", "bibliométrico". Como critérios de inclusão para que o material encontrado fosse analisado nesta pesquisa, foram separados todos os artigos que apresentavam em seu título um ou mais de um descritor utilizado. A figura 1, abaixo, apresenta o resumo da etapa metodológica da pesquisa. 
Figura 1 - Etapa metodológica da pesquisa

- Idealização da Pesquisa

- Consulta à Relevância da Fonte

- Aplicação dos Termos de Busca

- Leitura do Título e Resumo do Material Encontrado

- Exclusão do Material não Enquadradado

- Análise do Material que Apresentou Conformidade

- Discussões e Resultados

Fonte: Elaborada pelo autor.

Na pesquisa bibliométrica é essencial que o pesquisador elabore um script e siga cada passo, pois o método de estudo bibliométrico quando seguido em forma de etapas passa a garantir um rigor metodológico junto à eficácia do processo, além de entregar credibilidade ao trabalho elaborado. Contudo, é necessário que anterior à escolha do material que se pretende analisar, os pesquisadores definam uma ou mais bases de pesquisa, que pode ser livros, periódicos, jornais, dentre outras formas de literatura escrita em meios impressos e/ou virtuais. Após a escolha da base, buscas preliminares devem ser feitas para garantir que a definição da base não tenha sido precipitada, pois pode ocorrer de a base inicialmente apresentada como proposta, não apresente eficácia no processo de busca e análise do material encontrado, desta forma será necessário repensar descritores, bases ou até novas fontes de análise, o que pode atrasar o processo de pesquisa.

\section{APRESENTAÇÃO E ANÁLISE DOS RESULTADOS}

A operacionalização da busca realizada mostrou a existência de 80 trabalhos no site da ANPAD entre os anos de 2012 e 2016, enquanto no Spell foram identificados 272 artigos entre o período que compreende os meses de janeiro de 2014 e junho de 2018, dos quais após atenta leitura do título e resumo disponível, todos foram enquadrados dentro da análise. A leitura de títulos e resumos se faz necessária anterior à análise para garantir que o material está em conformidade com a proposta do trabalho. No mais, todos os artigos científicos encontrados foram produzidos e publicados com a temática bibliométrica. A leitura antecipada evidenciou ainda que alguns trabalhos que estavam presentes nos anais da ANPAD estavam disponíveis simultaneamente na base Spell, pois posterior à publicação nos eventos da Associação é comum que alguns passem por fast track, por exemplo, e sejam publicados em periódicos, desta forma, optou-se em 
dar prosseguimento às análises de cada base em separado para evitar equívocos com a possível supervalorização da produtividade de determinados autores.

\section{RESULTADO DA BUSCA NA BASE ANPAD}

No site da ANPAD não há opção se elaborar uma busca com uso simultâneo de todos os descritores, portanto, para encontrar os materiais necessários à análise, foram elaboradas três buscas com os descritores. Os resultados mostram que a indexação nesta base é feita a partir do título dos trabalhos, desta maneira é possível considerar que se novos autores pretendem destacar seus trabalhos com base numa indexação efetiva, é necessário considerar o título do trabalho como a forma de atrair atenção em buscas futuras. Nos estudos voltados para a bibliometria é a lei elaborada por Zipf (1949) que visa aprofundar as características dos textos quanto à presença e as repetições de palavras.

Desta forma, utilizar uma palavra coerente pode ser atraente ou conveniente para uma efetiva indexação do material produzido, contudo, é primordial para autores que buscam evidenciar seus trabalhos em meio aos demais a escolha assertiva dos termos que estarão presente em seu artigo a partir do título. É importante destacar que a utilização assertiva de uma palavra para indexação pode se tornar um ponto forte par que o trabalho não caia em outro princípio da bibliometria, que é a obsolescência (BURTON; KEBLER, 1960), ou seja, se o autor não tomar os devidos cuidados na escolha e utilização de um termo atrativo para seu trabalho, o estudo poderá cair no esquecimento, se tornar uma literatura não encontrada, não vista e não citada, a ponto de perder a validade para a temática estudada.

O gráfico 1, que segue, apresenta o quantitativo dos artigos encontrados de forma precisa com a utilização de cada descritor utilizado para os fins deste estudo. Os descritores são palavras utilizadas para indexação nas bases, peça essencial quando o interesse é destacar trabalhos a partir da busca por uma pesquisa.

Gráfico 1 - Quantidade de Artigos por Descritores

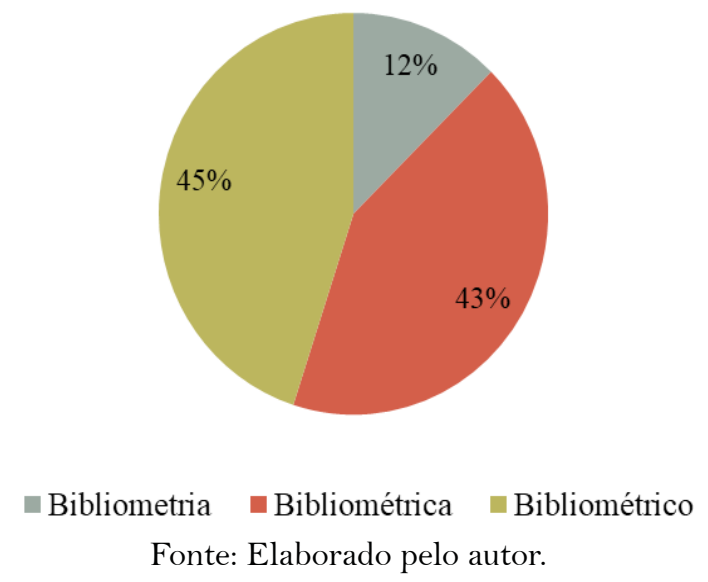


Como se observa ao considerar apenas a base da ANPAD, poucas pesquisas apresentaram o descritor "bibliometria" em seu título, totalizando apenas 10 artigos, equivalentes em média a $12 \%$ do total. Este resultado implica destacar que na necessidade de efetuar uma busca que apresente um volume considerável de trabalhos com a temática bibliométrica, os pesquisadores não devem considerar este descritor como o mais ideal. Por outro lado, os outros dois descritores utilizados apresentam resultado similar na base da ANPAD, visto que "bibliométrica" resulta em 34 e "bibliométrico" apresentou 36 trabalhos. Respectivamente $43 \%$ e $45 \%$ do total de trabalhos publicados no período considerado nesta pesquisa.

\section{NÚMERO DE PUBLICAÇÕES POR ANO EM ANAIS DA ANPAD}

Ao considerar o número de publicações anuais nos eventos elaborados pela ANPAD, levantamos a hipótese do interesse de pesquisadores e aceitação da temática nestes eventos. É sabido que a bibliometria é uma ferramenta importante quando se pretende destacar o status quo de uma temática ou as características da produção existente desta mesma temática. Desta forma, é relevante analisar o quantitativo de trabalhos elaborados baseados neste método, pois de maneira indireta, se entende que eles fomentam o princípio do Elitismo redigido por Braga (1973), já que é este núcleo da literatura recente que se mantém presente nas referências a relação com um pequeno grupo da produção mais antiga sobre bibliometria, sobretudo nas ciências administrativas e afins.

Os resultados após os levantamentos da literatura dos cinco anos considerados na base da ANPAD são apresentados abaixo no gráfico 2.

Gráfico 2 - Distribuição por Ano de Publicação

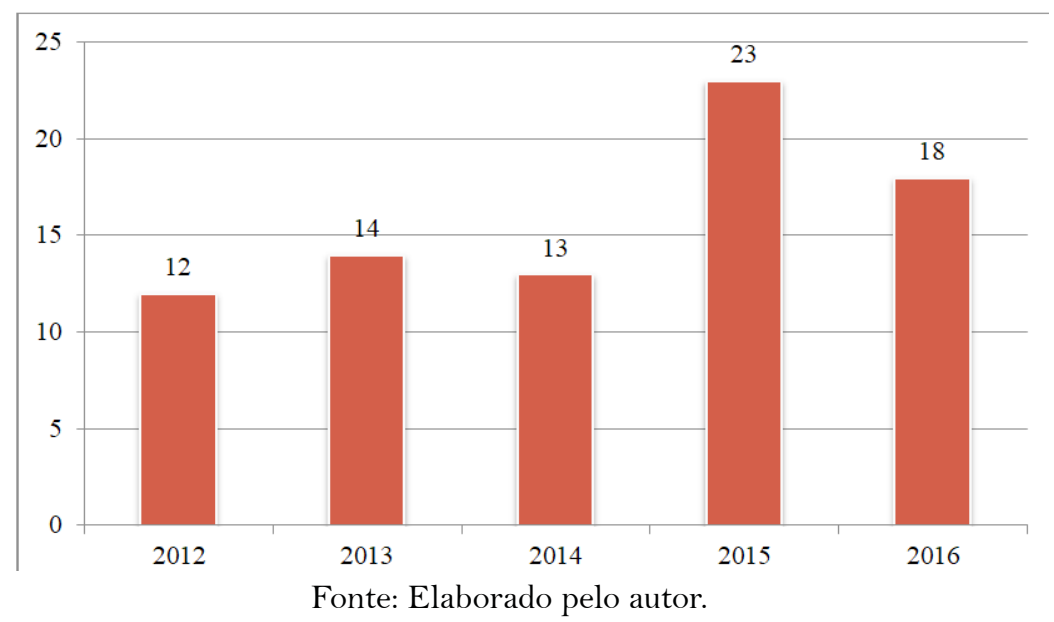

O gráfico destaca que o método bibliométrico é utilizado com uma frequência média de 16 trabalhos anuais, com realce para o ano de 2015 quando foram publicados 23 artigos bibliométricos nos eventos da ANPAD, número bastante elevado ante os anos de 2012 a 2014, que foram 12, 14 e 13 artigos respectivamente. Mensurar este quantitativo 
não é apenas revelar as relações com o elitismo da literatura, mas considerar que se houve aumento na produção, é possível que também exista ligação com o que preconiza o princípio epidêmico de Goffman e Newill (1964), pois se houve aumento consecutivo de um ano após o outro, este é um efeito de uma epidemia na produção científica quando alguém suscetível ao interesse foi exposto à pesquisa durante os eventos da ANPAD. Não obstante desta realidade, no ano de 2016 foram apresentados um número menor de artigos que é 2015, porém não menos considerável, já que é uma quantidade de produção acima da média, com 18 artigos ao total.

\section{NÚMERO DE ARTIGOS POR EVENTO DA ANPAD}

No que compreende o apoio à divulgação de trabalhos científicos na área das ciências administrativas no Brasil, é importante destacar a Associação Nacional de Pós-Graduação e Pesquisa em Administração (ANPAD), é uma instituição com sólido trabalho na promoção do ensino, pesquisa e produção de conhecimento dentro da administração pública e de empresas, contábeis e afins. Desta forma, desenvolve um calendário anual com promoção de eventos como congressos, encontros e simpósios, dentre outros.

Faz parte do calendário anual de eventos promovidos pela ANPAD os seguintes eventos: Encontro de Estudos Organizacionais - EnEO, Encontro de Administração Pública - EnAPG, Enconrto de Ensino e Pesquisa em Administração e Contabilidade - EnEPQ, Encontro de Marketing - EMA, Encontro de Gestão de Pessoas e Relações de Trabalho - EnGPR, Encontro de Administração da Informação - EnADI, Encontro de Estudos em Estratégias - 3Es, Encontro da Associação dos Programas de PósGraduação em Administração - EnANPAD e Simpósios. Diante da gama de opções para participação e submissão de produção científica por parte de estudiosos e pesquisadores, considerou-se destacar o quantitativo de trabalho por evento para nortear os interesses de pesquisadores que pretendem se deparar com trabalhos bibliométricos em eventos. O gráfico 3, apresenta o número de artigos por evento.

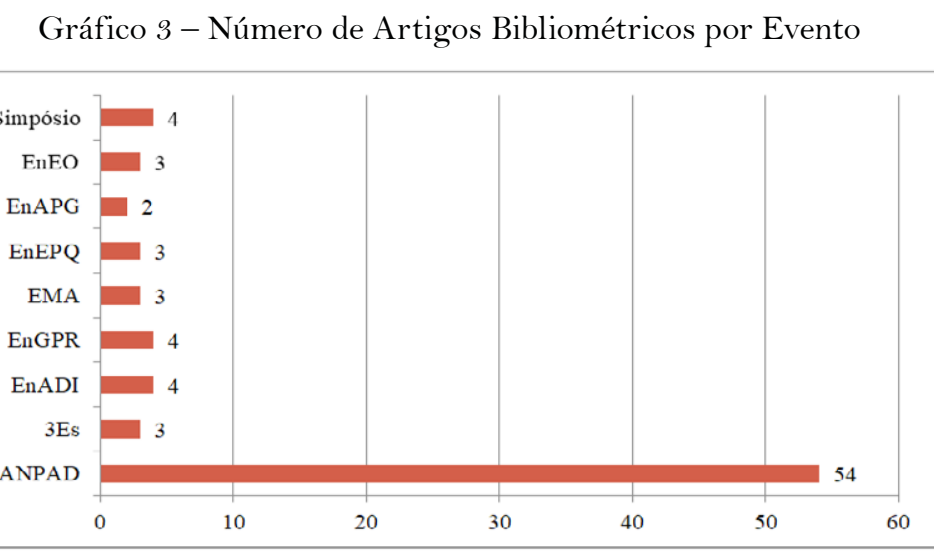

Fonte: Elaborado pelo autor. 
Este gráfico mostra que há um que é possível encontrar artigos bibliométricos em todos os eventos promovidos pela ANPAD, porém é o evento que tem atraído a maior quantidade de produção científica nesta direção metodológica é o EnANPAD. Este fato pode ser explicado pelo formato do evento, que é organizado a partir da divisão em grupos de discussões temáticas que agregam temas de diversos interesses nas ciências administrativas e áreas afins. Porém, quando analisamos este fenômeno, podemos considerar que, em termos de produção científica sobre bibliometria, os anais do EnANPAD em detrimento dos demais eventos promovidos, é a representação da lei de Bradford (1934). Pois, é notório que este evento se apresenta como um núcleo de produção científica e está relacionado de maneira próxima à temática da bibliometria quando comparado aos demais eventos, portanto apresenta um o maior volume de trabalhos bibliométricos, equivalente a $67,5 \%$ de todos os trabalhos encontrados nos anais de todos os eventos da ANPAD.

\section{QUANTIDADE DE AUTORES E COAUTORES NA BASE ANPAD}

É permitida a submissão de trabalhos elaborados por um só autor ou na forma de coautoria, que é quando há mais de um autor desenvolvendo o trabalho científico. É relevante considerar a quantidade de autores nos trabalhos científicos presentes nos anais dos eventos da ANPAD para mensurar como critério, a efetividade de grupos de pesquisa como forma de avançar na produtividade dos materiais com características bibliométricas. O gráfico 4 abaixo explicita com exatidão este tipo de análise.

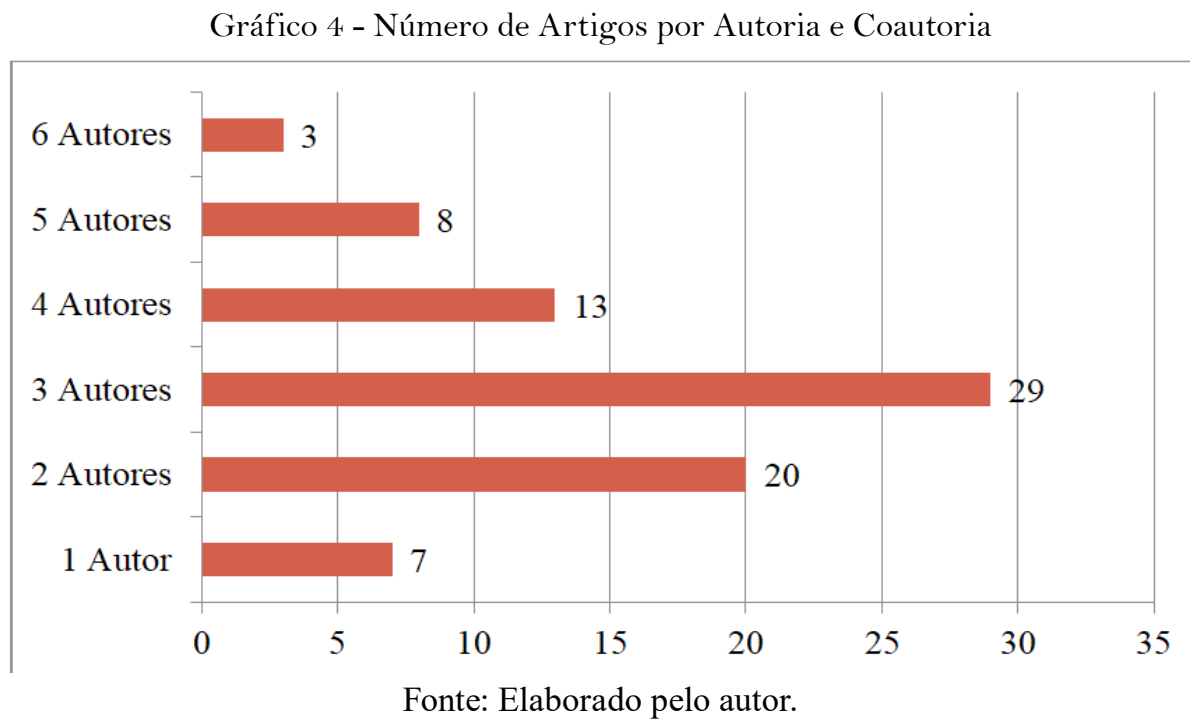

Ao analisarmos o gráfico acima é possível evidenciar que é comum a participação de grupos de autores na elaboração de trabalhos bibliométricos, pois apenas 7 trabalhos foram elaborados por autores individuais, enquanto 73 trabalhos tiveram a presença 
de pelo menos dois autores. Em termos de produtividade não é correto destacar que a quantidade de coautores esteja intimamente relacionada a uma quantidade maior de artigos e pesquisas publicadas, porém é possível destacar que diante da dificuldade em se elaborar pesquisas bibliométricas, a formação de grupos de pesquisas para esta finalidade tem sido uma saída praticada pela maior parte dos autores.

A pesquisa bibliométrica, embora muito presente na literatura, pode ser de difícil elaboração, pois para que ela seja desenvolvida, frequentemente há a necessidade de se organizar uma vasta busca de materiais para posterior leitura e assimilação de características como variáveis de análise. É essencial ainda, que antes da organização dos materiais haja a definição de termos de busca ou indexadores inerentes a área a qual se pretende investigar, além da validação das bases ou fontes de pesquisas para o refinamento dos resultados. Cuidados deste tipo se tornam úteis para se evitar questionamentos e conflitos com supervalorização ou subvalorização de aspectos relevantes na pesquisa apresentada.

\section{RESULTADOS DA BUSCA NA BASE SPELL}

Para obter este resultado foram mantidos os mesmos passos conduzidos anteriormente na base ANPAD. Porém, é importante lembrar que a indexação na base Spell pode ser pelo título, resumo, palavra chave, dentre outros, o que amplia a possibilidade de destaque para os trabalhos indexados. Os resultados das buscas mostram que entre janeiro de 2004 e junho de 2018 foram publicados 272 artigos relacionados à temática bibliométrica em 85 ou aproximadamente $70,25 \%$ do total de 121 periódicos indexados. Desta maneira, é importante frisar que diferente dos anais da ANPAD que são indexados baseados apenas no título dos artigos, para uma indexação mais atraente na base Spell, cabe aos autores considerar com a devida razoabilidade a presença dos três descritores entre a formulação do título, resumo e palavras-chave. Feito desta forma, o autor possibilitará que seu artigo apareça em qualquer uma das formas de busca, potencializará a presença a partir do uso da palavra. Nos estudos voltados para a bibliometria, Zipf (1949) determina que a palavra que é possível mensurar a palavra que mais se repete no texto, e este cálculo auxilia na indexação do texto à temática. O gráfico 5 abaixo apresenta os resultados para cada palavra-chave aplicada nesta pesquisa.

Tabela 1 - Quantidade de Artigos por Descritores

\begin{tabular}{|c|c|c|}
\hline DESCRITOR & QUANTIDADE & $(\%)$ \\
\hline Bibliometria & 29 & 10,58 \\
\hline Bibliométrica & 118 & 43,07 \\
\hline Bibliométrico & 125 & 46,35 \\
\hline TOTAL & 272 & 100 \\
\hline
\end{tabular}

Fonte: Elaborada pelo autor. 
Os resultados mostram que nesta base, também há preferência pelo uso dos descritores "bibliométrica" e "bibliométrico", que representam 43,07\% e 46,35\% dos resultados respectivamente. Desta forma, utilizar o descritor "bibliometria” tem sido a opção minoritária dos autores, com apenas 10,58\% dos trabalhos encontrados.

\section{PRODUTIVIDADE ANUAL NA BASE SPELL}

Para a análise deste tópico a plataforma Spell não disponibilizou os resultados anuais do ano de 2017 e do período entre janeiro e junho de 2018. Porém, o resultado mostra que no período que compreende o ano de 2004 até 2006, apenas dois trabalhos foram lançados no cenário nacional registrado na plataforma Spell, contudo, os anos de 2005 e 2006 nenhum foram registrados qualquer resultado. Esta ocorrência demonstra que a técnica bibliométrica não era pouco explorada na área das ciências administrativas e afins. Entretanto, a partir do ano de 2007, tem-se registrado novos trabalhos com um grande pico de produtividade no ano de 2016, quando foi publicado um total de 51 trabalhos nos periódicos nacionais. A média de produção considerando todos os anos pesquisados é de 17 trabalhos anuais, mas o desvio padrão desta produtividade é de 18,41. A tabela 2 , abaixo, apresenta o quantitativo por ano.

Tabela 2 - Produtividade por ano

\begin{tabular}{|c|c|c|c|}
\hline ANO & QUANTIDADE & ACUMULADO & $\%$ \\
\hline 2004 & 2 & 2 & 0,90 \\
\hline 2005 & 0 & 2 & 0,90 \\
\hline 2006 & 0 & 9 & 0,90 \\
\hline 2007 & 2 & 13 & 1,81 \\
\hline 2008 & 5 & 22 & 4,07 \\
\hline 2009 & 4 & 33 & 5,88 \\
\hline 2010 & 9 & 57 & 9,95 \\
\hline 2011 & 11 & 99 & 14,93 \\
\hline 2012 & 24 & 127 & 25,79 \\
\hline 2013 & 42 & 170 & 44,80 \\
\hline 2014 & 28 & 221 & 57,47 \\
\hline 2015 & 43 & - & 76,92 \\
\hline 2016 & 51 & - & 100,00 \\
\hline 2017 & $\mathrm{D} / \mathrm{I}$ & $\mathrm{2}$ & - \\
\hline Jan/jun 2018 & $\mathrm{D} / \mathrm{I} *$ & 2 & - \\
\hline
\end{tabular}

$\mathrm{D} / \mathrm{I}^{*}=$ Dados Indisponíveis

Fonte: Elaborada pelo autor.

Os resultados mostram que o desenvolvimento de pesquisas baseadas na técnica bibliométrica tem sido usual no cenário dos periódicos nacionais. A ocorrência do aumento no volume deste tipo de pesquisa evidencia o efeito epidêmico baseado na 
teoria de Goffman e Newill (1964), pois é possível perceber que a partir de 2007, com a divulgação de dois trabalhos, há uma crescente na divulgação da produção anualmente pelo menos até 2013 com 42 trabalhos sendo expostos. No ano de 2014 há uma queda na produção se comparado ao ano anterior, com 28 artigos publicados. Merece destacar que em 2015 e 2016 há uma maior produtividade com 43 e 51 trabalhos encontrados nos periódicos nacionais respectivamente.

\section{PRODUTIVIDADE POR AUTOR}

Mensurar a produtividade por autor é uma forma de identificar indícios da Lei de Lotka (1926) e, nesta lei, o autor considera que um núcleo pequeno de autores tem uma maior representatividade de produção quando em detrimento da produção de um grande grupo de outros autores. Com isto, Lotka (1926) busca estimar o grau relativo da produtividade ou a relevância dos autores em uma área específica do conhecimento (GUEDES, 2012). Desta forma, ao avaliar a plataforma foi possível identificar que alguns autores se destacam pela grande produtividade em material bibliométrico, portanto foram considerados para fins desta análise apenas os autores que apresentaram pelo menos quatro artigos publicados. A relação dos autores mais profícuos é apresentada na tabela 3 abaixo para nortear à análise.

Tabela 3 - Ranking da produtividade por autor

\begin{tabular}{|c|c|c|}
\hline RANKING & AUTOR(A) & QUANTIDADE \\
\hline $1^{\circ}$ & Henrique César Melo Ribeiro & 6 \\
\hline $2^{\circ}$ & Daniela Torres da Rocha & 6 \\
\hline $3^{\circ}$ & Fernando Ribeiro Serra & 6 \\
\hline $4^{\circ}$ & Leonardo Ensslin & 6 \\
\hline $5^{\circ}$ & Manuel Portugal Ferreira & 5 \\
\hline $6^{\circ}$ & Claudia Terezinha Kniess & 5 \\
\hline $7^{\circ}$ & Fernando Antônio Ribeiro Serra & 5 \\
\hline $8^{\circ}$ & Gabriela Gonçalves Silveira Fiates & 5 \\
\hline $9^{\circ}$ & June Alisson Westerb Cruz & 5 \\
\hline $10^{\circ}$ & Maria Tereza Saraiva de Souza & 5 \\
\hline $11^{\circ}$ & Rosany Corrêa & 4 \\
\hline $12^{\circ}$ & Celso Machado Junior & 4 \\
\hline $13^{\circ}$ & Irene Raquenet Troccoli & 4 \\
\hline $14^{\circ}$ & João Carvalho Santos & 4 \\
\hline $15^{\circ}$ & Jonas Lucio Maia & 4 \\
\hline $16^{\circ}$ & Luiz Antonio de Camargo Guerrazzi & 4 \\
\hline $17^{\circ}$ & Mauro Carlos Di Serio & 4 \\
\hline $18^{\circ}$ & & \\
\hline
\end{tabular}

Fonte: Elaborado pelo autor. 
O resultado mostra que são 18 autores que apresentam pelo menos quatro trabalhos elaborados e publicados em periódicos nacionais indexados na plataforma Spell. O ranking evidencia que o pesquisador Henrique César Melo Ribeiro se destaca com 17 pesquisas bibliométricas. Evidenciar os autores mais profícuos pode auxiliar na identificação dos núcleos de pesquisa que pode estar na dianteira do estudo quanto a perspectiva bibliométrica, pois Guedes (2012) acredita que quanto mais solidificada estiver uma ciência, maior probabilidade de seus autores produzirem múltiplos artigos, em dado período de tempo.

\section{PERIÓDICOS MAIS PROFÍCUOS}

A objetivação de identificar os periódicos mais profícuos vem da perspectiva determinada por Guedes (2012) para aplicação da Lei de Bradford, que é um instrumento útil para a elaboração de políticas de busca, aquisição e de descarte de periódicos, quando da necessidade de se conseguir alguma informação de uma determinada área de pesquisa. Esta lei auxilia no gerenciamento da informação e do conhecimento científico e tecnológico, pois a partir dela é possível estimar a amplitude e magnitude de determinada área bibliográfica e o custo de toda e qualquer fração específica da bibliografia, no todo. Desta forma, a tabela 4 abaixo apresenta o ranking dos periódicos que mais apresentam trabalhos voltados para a bibliometria.

Tabela 4-Ranking da produtividade por periódico

\begin{tabular}{|c|c|c|}
\hline RANKING & PERIÓDICO & QUANTIDADE \\
\hline $1^{\mathrm{o}}$ & Perspectivas em Gestão \& Conhecimento & 11 \\
\hline $2^{\circ}$ & Revista de Ciências da Administração & 10 \\
\hline $3^{\circ}$ & $\begin{array}{c}\text { Reunir: Revista de Administração, Contabilidade e Sustenta- } \\
\text { bilidade }\end{array}$ & 9 \\
\hline $4^{0}$ & Revista de Gestão e Projetos & 8 \\
\hline $5^{\mathrm{o}}$ & Administração: Ensino e Pesquisa & 7 \\
\hline $6^{\circ}$ & Pensar Contábil & 7 \\
\hline $7^{\circ}$ & Revista Eletrônica de Estratégia \& Negócios & 7 \\
\hline $8^{\circ}$ & Revista Gestão \& Tecnologia & 7 \\
\hline $9^{\circ}$ & $\begin{array}{c}\text { Contexto - Revista do Programa de Pós-Graduação em Con- } \\
\text { troladoria e Contabilidade da UFRGS }\end{array}$ & 6 \\
\hline $10^{\circ}$ & $\begin{array}{l}\text { InternexT - Revista Eletrônica de Negócios Internacionais } \\
\text { da ESPM }\end{array}$ & 6 \\
\hline $11^{\circ}$ & Revista Eletrônica Gestão e Serviços & 6 \\
\hline $12^{\circ}$ & Revista Ibero-Americana de Estratégia & 6 \\
\hline $13^{\circ}$ & Contabilidade, Gestão e Governança & 5 \\
\hline $14^{\circ}$ & Revista Alcance & 5 \\
\hline $15^{\circ}$ & Revista de Administração Contemporânea & 5 \\
\hline
\end{tabular}




\begin{tabular}{|c|c|c|}
\hline $16^{\circ}$ & Revista de Administração da Unimep & 5 \\
\hline $17^{\circ}$ & Revista de Gestão & 5 \\
\hline $18^{\circ}$ & Revista de Gestão e Secretariado & 5 \\
\hline $19^{\circ}$ & Revista Organizações em Contexto & 5 \\
\hline
\end{tabular}

Fonte: Elaborado pelo autor.

Foram considerados neste ranking apenas os periódicos que apresentaram pelo menos 5 artigos científicos cujo o método de estudo estava baseado na bibliometria. Desta forma, os resultados da pesquisa mostram que o periódico 'Perspectivas em Gestão \& Conhecimento’ é o que mais publica material quando o assunto é bibliometria, seguido por 'Revista de Ciências da Administração' com 10 artigos bibliométricos, logo após aparece o periódico 'Reunir - Revista de Administração, Contabilidade e Sustentabilidade' com 9 artigos. Em si tratando de periódicos que podem servir de base para a compreensão e efetividade da técnica bibliométrica, então, é possível considerar os 19 periódicos nacionais presentes na tabela 4, já que compreendem 45,96\% de toda a produção nacional considerada nas análises deste trabalho.

\section{CONSIDERAÇÕES FINAIS}

No que compreende o apoio à divulgação de trabalhos científicos na área das ciências administrativas no Brasil, é importante destacar a Associação Nacional de PósGraduação e Pesquisa em Administração (ANPAD). Portanto, esta pesquisa evidenciou o papel da ANPAD na divulgação de trabalhos voltados para a técnica bibliométrica no Brasil, pois foi encontrado nos anais dos eventos entre 2012 e 2016 um total de 80 trabalhos. Por ser uma instituição com sólido apelo à promoção do ensino, pesquisa e produção de conhecimento dentro da administração, contábeis e afins, é primordial que este trabalho de ceder espaços em eventos para publicação dos artigos baseados em pesquisas com desenvolvimento a partir do enfoque bibliométrico continue a existir. Ao mesmo tempo, a base de pesquisa Spell se apresentou como uma fonte enriquecida de materiais com este mesmo enfoque, pois dos 121 periódicos indexados, pelo menos 85 apresentaram algum artigo com a temática bibliométrica no cenário nacional.

O trabalho se propôs a elaborar uma análise da produção de estudos científicos nos anais dos encontros promovidos pela ANPAD entre os anos de 2012 e 2016, bem como na base de indexação Spell, que apresentou resultados entre 2004 e junho de 2018. Para tal, foram considerados dentro da pesquisa os trabalhos que apresentavam em seu título os descritores definidos na etapa metodológica que foram: bibliometria, bibliométrica, bibliométrico, que foram capazes de evidenciar que nos últimos anos as ciências administrativas e áreas afins estão se aproximando e se apoderando com a devida intimidade da ferramenta da análise bibliométrica como importante método de pesquisa. Dentre as descobertas que foram possíveis, está a evidenciação de que os estudos bibliométricos tem marcado presença nos eventos e periódicos nacionais. 
Quanto aos eventos patrocinados pela ANPAD entre 2012 e 2016, o EnANPAD se destaca apresentando 54 artigos bibliométricos em seus anais. Por outro lado, desde o ano de 2007, que de maneira consecutiva, os periódicos nacionais da área da administração, contábeis e afins, vêm apresentando trabalhos de cunho bibliométrico, sendo o ano de 2016, que finaliza o período considerado para fins deste estudo, o ano que apresentou mais publicações, totalizando 51 artigos científicos, que equivalem a $18,75 \%$ do total de artigos encontrados na base Spell entre 2004 e 2016. Destacase ainda a presença de 19 periódicos nacionais que podem ser núcleos de trabalhos bibliométricos, pois apresentam pelo menos 5 trabalhos voltados para a temática, em especial o periódico 'Perspectivas em Gestão \& Conhecimento' apresentou um volume de 11 trabalhos, o que o torna a maior fonte em si tratando desta categoria de análise. No que compreende aos autores, temos que 18 autores tinha participação em pelo menos 4 trabalhos elaborados e, Henrique César Melo Ribeiro apresenta participação em 17 trabalhos, o que o torna o mais produtivo autor a nível nacional.

É importante ainda reforçar, que dentre as limitações desta pesquisa, esteve a necessidade de efetuar pagamento à ANPAD para poder ter acesso aos anais de eventos. Bem como, fazer pesquisas e buscas específicas na plataforma Spell, pois ela se demonstrou instável, ao tempo que também não apresentou os resultados dos anos de 2017 e 2018 o que comprometeu um resultado ainda mais recente.

Por fim, com base nos resultados expostos é possível evidenciar como conclusão deste trabalho que a técnica bibliométrica tem sido explorada na ciência da administração, contábeis e áreas afins, em função da sua importância como método eficaz para a gestão da informação e do conhecimento nas ciências administrativas e áreas correlacionadas.

\section{REFERÊNCIAS}

ARAÚJO, C. A. Bibliometria: evolução histórica e questões atuais. Em Questão, v. 12, n. 1, p. 11-32, 2006.

ANPAD. Associação Nacional de Pós-Graduação e Pesquisa em Administração. Disponível em: <http://www.anpad.org.br>. Acesso em: 25 mar. 2018.

BRADFORD, S. C. Sources of information on specific subjects. Engineering, v. 137, n. 3550 , p. 85-86, 1934 .

BRAGA, G. M. Relações bibliométricas entre a frente de pesquisa (research front) e revisões da literatura: estudo aplicado à ciência da informação. $C i$. Inf., v. 2, n. 1, p. 9-26, 1973.

BURTON, R. E.; KEBLER, R. W. The "half-time" of some scientific and technical literatures. American Documentation, v. 11, p. 18-22, 1960. 
COILE, R. C. Lotka's frequency distribution of scientific productivity. Journal of the American Society for Information Science, 1977.

GUEDES, V. L. S. A bibliometria e a gestão da informação e do conhecimento científico e tecnológico: uma revisão da literatura. PontodeAcesso, v. 6, n. 2, p. 74-109, 2012.

INEP. Instituto Nacional de Estudos e Pesquisas Educacionais Anísio Teixeira. Disponível em: < http://portal.inep.gov.br> Acesso em 25 de mar. de 2018

KÖCHE, José Carlos. Fundamentos de metodologia científica: teoria da ciência e iniciação à pesquisa. Petrópolis, RJ: Vozes, 2011.

LIEVORE, C.; PICININ, C. T.; PILATTI, L. A. As áreas do conhecimento na pósgraduação stricto sensu brasileira: crescimento longitudinal entre 1995 e 2014. Ensaio: aval. Pol. Public. Educ., v. 25, n. 94, p. 207-237, 2017.

LOTKA, A. J. The frequency distribution of scientific productivity. Journal of the Washington Academy of Science. v. 16, n. 12, p. 317-323, 1926.

MORENO, J. L. Fundamentos de la sociometria. Buenos Aires: Editorial Paidos, 1962.

OLIVEIRA, E. F. T.; GRACIO, M. C. C. Indicadores bibliométricos em ciência da informação: análise dos pesquisadores mais produtivos no tema estudos métricos na base Scopus. Perspectivas em Ciência da Informação, v. 16, n.4, 2011.

PRITCHARD, A. Statistical bibliography or bibliometrics? Jornal of Documenfation, v. 25 , n. 4, p. 348-349, 1969.

SPELL. Scientífic Periodicals Eletronic Library. Disponível em: <http://www.spell. org.br> Acesso em: 10 de jun. de 2018

URBIZAGÁStEGUI ALVARADO, R. A bibliometria no Brasil. Ci. Inf. v. 13, n. 2, p.91-115, 1984 .

ZIPF, G. K. Human behavior and the principle of least effort. Cambridge, Ma: Addison Wesley, 1949. 